\title{
Depressive Symptoms, Body Mass Index, and Physical Activity Self- Efficacy in African American Children
}

\author{
Y'Esha V. Williams $\mathbb{1}^{1} \cdot$ Patricia A. Cowan ${ }^{2}$. Joyce C. Graff ${ }^{3}$
}

Published online: 27 June 2020

(c) Springer Science+Business Media, LLC, part of Springer Nature 2020

\begin{abstract}
In recent decades, the prevalence of childhood depression and obesity has increased worldwide. African American (AA) children are more obese than White peers and experience many factors that can influence the onset of depressive symptoms. While depression and obesity have been examined in adolescents, there is a paucity of research in AA children. This study examined the relationships among depressive symptoms, obesity, and physical activity self-efficacy in AA children. A community sample of 65 AA children completed questionnaires for depressive symptoms and physical activity self-efficacy and also had body mass index (BMI) and BMI Z-scores calculated. Correlational statistics were used to examine associations between variables. Clinically significant total depression scores were present in $22 \%$ of children, while $48 \%$ were overweight or obese. Overall, children reported high physical activity self-efficacy. Higher depressive symptoms were associated with higher BMI Z-scores. Results also indicated significant correlations between the children's physical activity self-efficacy and depressive symptoms. Findings suggest that the associations between depressive symptoms, BMI, and physical activity selfefficacy in AA children merit additional examination. Early identification of depression in children may inform future approaches to treatment of psychological and physiological problems within the clinical setting. Screening for childhood depressive symptoms in primary care settings, especially those that specifically treat childhood obesity, can be instrumental in early identification of children with depression. Healthcare providers should be knowledgeable of the clinical presentation of depression and engaged in depression screening.
\end{abstract}

Keywords African Americans $\cdot$ Childhood depression $\cdot$ Childhood obesity $\cdot$ Physical activity $\cdot$ Self-efficacy

\section{Highlights}

- Twenty-two percent of children reported clinically significant depressive symptoms.

- Negative mood/physical symptoms occurred in $25 \%$ of children.

- Higher BMI Z-scores were associated with greater interpersonal problems.

- Physical activity self-efficacy was high among the children at every BMI.

$\triangle$ Y'Esha V. Williams

yvwllams@memphis.edu

1 University of Memphis Loewenberg College of Nursing, 3566 Community Health Building, Memphis, TN 38152, USA

2 University of Arkansas for Medical Sciences, College of Nursing, 4301W. Markham, Slot 529, Little Rock, AR 72205, USA

3 University of Tennessee Health Science Center, College of Nursing, 5th Floor, 920 Madison Avenue, Memphis, TN 38163, USA
Depression is one of the most common and debilitating mental disorders, yearly affecting millions of people worldwide (U.S. Department of Health and Human Services \& National Institute of Mental Health 2015). Within the last few decades, childhood and adolescent depression has emerged as a research priority, both because of the increase in prevalence and because of the emerging tendency to consider mental health as a vital component of the overall health of a child. The Anxiety and Depression Association of America (2016) estimates that about 3\% of children 6-12 years of age may experience depression. Past studies have shown that adolescent girls are twice as likely to experience depression in comparison to male counterparts, and this 
ratio is approximately equivalent to the ratio seen in gender differences in adulthood (Derry et al. 2015; Mazurka et al. 2018; Merikangas et al. 2010).

Depressive disorders are multifaceted, and manifestations of depressive symptomatology vary between individuals. However, a combination of genetic, environmental, and psychological factors are linked with the development of depression (National Institute of Mental Health 2016). Currently, there is a lack of information on national childhood depression statistics in African American (AA) children. However, studies involving AA children and adolescents have indicated specific risk factors for the development of depression, including the experience of racial discrimination (English et al. 2014) and exposure to increased interparental conflict (Barton et al. 2015). In addition, residing in unsafe neighborhoods, with higher exposure to violence and stressful life events, also contributes to depressive symptoms in AA youth (Assari and Caldwell 2017; Washington et al. 2017).

Depressive disorders of any magnitude can ultimately interfere with a child's daily life and can decrease their quality of life extensively. Self-injury behaviors, decreased scholastic achievement (Auerbach 2015), increased substance abuse, dysfunctional relationships, and suicidal ideations are only a few of the negative consequences of depression in children and adolescents (Mental Health America 2018). Treatment for depressive symptoms is vital in children and adolescents because, over time, unchecked symptoms can affect their mental health status into adulthood.

Similar to increases in the prevalence of depression, there has been a significant increase in the rates of overweight and obese individuals worldwide. The prevalence of overweight and obese American children nearly tripled over the last three decades (American Heart Association 2014) but has remained stable over the last few years in children aged 6-11 years (Ogden et al. 2016). However, between 2013-2014, researchers reported significant increases in the prevalence of extremely obese children within that age range (Ogden et al. 2016). Moreover, racial differences in youth obesity trends have been well studied, and the prevalence of obesity in minority children and adolescents is substantially higher in comparison to other races. The Centers for Disease Control and Prevention (2018b) (CDC) confirmed that approximately $25.8 \%$ of Hispanic, $22 \%$ of non-Hispanic Black, and $14.1 \%$ of non-Hispanic White children and adolescents 2-19 years of age are identified as obese.

Possible causes for the upsurge in childhood obesity rates have been well documented within the literature. Unhealthy eating habits, limited access to (and affordability of) healthier foods, and increases in sugary beverage intake are documented causes of childhood obesity (Alliance for a
Healthier Generation 2016). In addition, a lack of daily physical activity and genetic predispositions are among the identified risk factors leading to childhood obesity (Kumar and Kelly 2017). If left untreated, hypertension and cardiovascular disease are among the many comorbid conditions associated with childhood obesity that can persist, becoming a lifelong problem (Han et al. 2010; Lakshman et al. 2012; Sommer and Twig 2018).

Although obesity is considered a preventable disease, current recommendations for the treatment of obesity suggest lifestyle and behavioral modifications. Contrary to the belief that children are physically active, researchers insist that today's children lead more sedentary lifestyles, with a reduction in physical activity and an increase in time spent with screen-oriented technology, such as video games and television (U.S. Department of Health and Human Services President's Council on Fitness Sports \& Nutrition 2015; Williams et al. 2008). The current childhood obesity epidemic has prompted an immediate, worldwide call for children to increase physical activity in order to combat this problem. The Office of Disease Prevention and Health Promotion (2016) has established healthy physical activity guidelines for youth in the United States. According to these guidelines, children and adolescents should perform a minimum of $60 \mathrm{~min}$ of aerobic physical activity daily to decrease body fat and have healthier body compositions.

Self-efficacy, a person's belief in their ability to achieve a particular goal, is known to help facilitate the act of physical activity (Hamilton et al. 2017), which can potentially aid in weight management. Bandura (1989) states that self-efficacy is important to the cognitive process because it allows for goal-setting and the motivation to accomplish the desired outcome. Goal-setting is essential to behavioral changes because it sets limits on unhealthy routines and creates a sense of accomplishment when goals are attained (Gu et al. 2018; Lorig and Holman 2003). In addition, selfefficacy also permits individuals to believe in themselves and in their capability to execute specific actions, such as weight reduction through behavioral changes (Coleman and Newton 2005; Flanagan and Perry 2018). Physical activity self-efficacy affords individuals the opportunity to evaluate the results of their actions; therefore, more physical activity will be performed if the expectations of losing weight are met (Dishman et al. 2005; Flanagan and Perry 2018). Examining the connections between self-efficacy and childhood outcomes such as body mass index (BMI), depressive symptoms, and physical activity is important; however, more research is needed to validate these associations.

To date, few studies have explored depressive symptoms and its associations with physical activity self-efficacy in AA children; more research has been devoted to depressive symptoms among AA adolescents and adults. The current 
study addressed these issues by examining the relationships among depressive symptoms, BMI, and physical activity self-efficacy in AA children 7-10 years of age. Three hypotheses were tested: (1) child depressive symptoms would be positively associated with more overweight-toobese body compositions, expressed as BMI Z-scores, (2) child depressive symptoms would be negatively associated with physical activity self-efficacy, and (3) children with overweight and obese body compositions (expressed as BMI Z-scores) would be negatively associated with physical activity self-efficacy.

\section{Methods}

\section{Participants}

This study was designed as a cross-sectional, descriptive, correlational study of depressive symptoms, BMI, and physical activity self-efficacy relationships in AA children. After receiving approval to conduct the study from the university institutional review board, a convenience sample of 65 children from Memphis, TN, was recruited through flyers posted at local churches, elementary schools, a local University, and community centers. Both mothers and fathers were eligible to enroll their children in the study; however, all participants were enrolled by their mothers (i.e., no fathers participated in the study). Therefore, the mothers were the primary source of information for the child participants. An initial telephone screening process with each participant's mother also played a role in determining eligibility for participation. This screening process allowed the investigators to determine whether the child met the specific inclusion criteria by asking the mother questions about the child's age, race, first language, and physical ability.

Children were eligible to participate in the study if (1) the mother identified them as AA or AA/biracial, (2) they were 7-10 years of age, and (3) they had the ability to stand upright without assistance. In addition, it was necessary for the child to read and speak in English in order to respond appropriately to the depressive symptom and physical activity self-efficacy self-report instruments. Both male and female participants were accepted. Children's BMI percentiles represented normal weight, overweight, and obese categories.

\section{Procedure}

Upon meeting all inclusion criteria for participation, individuals were provided with a date, time, and location to meet with the study investigator. On the day of participation, study concepts, purpose, and procedures were discussed with all children participants and the mothers. In addition, information about receiving incentives upon completing the study was addressed and each mother signed a consent form for their child. Children 8 years and older signed assent forms to participate, and children 7 years of age did not have to sign assent forms, per IRB requirements. Before beginning the study, mothers and children were encouraged to ask questions to gain a better understanding of the study. Children were informed that participation was strictly voluntary and were asked if they understood the study's purpose, the data to be collected, and the procedures for data collection.

After completing the paperwork, height and weight measurements of each child participant were collected to calculate BMI and correlating BMI Z-scores. Away from the parent, the child completed a depressive symptom selfinventory, which asked about personal feelings over the past 2 weeks, and a physical activity self-efficacy inventory that inquired about their physical activity behaviors. Both assessments are described in greater detail in the sections that follow.

\section{Measures}

\section{Demographic information}

Each mother was provided a Demographic Profile Questionnaire for reporting demographic information about the child participant (ethnicity, gender, age, current grade, physical address). The Demographic Profile Questionnaire also included a medical information section in which the mother answered questions about the child's health and current medical conditions.

\section{Body mass index percentile Z-score (BMI Z-score)}

Although BMI does not measure body fat directly, it can be a general indication of a person's body fat (Centers for Disease Control and Prevention 2018a). The researcher measured each participant's height in inches using a stadiometer and weight in pounds with a scale. BMI was then calculated by converting weight to kilograms, which was divided by the square of the height converted to meters $(\mathrm{kg} /$ $\mathrm{m}^{2}$ ). In pediatric populations, ages 2-19 years, a numeric measurement of BMI was calculated comparable to adults. The BMI was then plotted on a standardized BMI-for-age and gender percentile chart. The chart allows for an inexpensive and less invasive mechanism for tracking increases or decreases in youth adiposity over time, compared to national normative standards (Centers for Disease Control and Prevention 2015a). In addition, BMI-for-age percentile charts are used to determine BMI percentiles that can be correlated with national data from the National Health and Nutrition Examination Survey (NHANES). Normal weight 
ranges from greater than or equal to the 5 th percentile to less than the 85th percentile. Overweight ranges from greater than or equal to the 85 th percentile to less than the 95 th percentile, and obesity is greater than or equal to the 95th percentile (Centers for Disease Control and Prevention 2018a). To better quantify extreme BMI percentiles that were above the top percentile on the pediatric growth chart, $Z$-scores, standard deviations above and below the mean at the 50th percentile, were calculated using The Children's Hospital of Philadelphia (2016) online Pediatric Z-score Calculator.

\section{Depressive symptoms}

Depressive symptoms in children were measured using the Children's Depression Inventory 2TM (CDI 2). The CDI 2 is a 28-item, multiple-choice, self-report screening tool used to assess symptoms of depression in children and adolescents ages 7-17 years (Kovacs and Multi-Health Systems 2011). From a list of three sentences, the child respondent chose the answer that best addressed their feelings and emotional and physical state within the last 2 weeks. Scores for each question were rated from 0 to 2 , where a score of 0 signified normalcy and no depressive symptoms. A score of 1 indicated a depressive symptom that is not disabling, while a score of 2 was the highest, indicating a clinically depressive symptom (Kovacs and Multi-Health Systems 2011).

In regard to the Diagnostic and Statistical Manual of Mental Disorders (DSM-IV) criteria for depression, the CDI 2 provides an overall total score for depressive symptoms; it includes two scales that assess emotional problems and functional problems, as well as four subscales that measure negative mood/physical symptoms, negative self-esteem, ineffectiveness, and interpersonal problems. Each item on the CDI 2 is categorized in one of the four subscales, and the sum of all items in that category provides an overall score for the particular subscale. Together, the addition of two subscales (negative mood/physical symptoms and negative selfesteem) comprise the raw score for emotional problems. Likewise, the raw score for functional problems is the sum of the two subscales (ineffectiveness and interpersonal problems). The overall total score is calculated by summing the scores of the emotional and functional problems scales. In this study, scores were reported for all four subscales, the two scales, and the overall total score.

Considering age and gender differences, the raw scores for the overall total score, two scales, and four subscales were converted to $T$-scores for standardization. Average to high-average, elevated, and very elevated scores ranged from $\leq 40-64,65-69$, and $\geq 70$, respectively. Previous researchers have established reputable psychometric properties for the CDI 2 (Kovacs and Multi-Health Systems 2011). In a sample of 1100 American children (24.1\% AA) ages 7-19, an alpha of 0.91 was obtained for the overall total score, indicative of high internal consistency. The overall total score also reflected high coefficient alphas (0.88-0.92) when examining gender and age groups independently. The CDI 2 has improved psychometric properties in relation to the original Children's Depression Inventory $\left(\mathrm{CDI}^{\mathrm{TM}}\right)$, which reports an alpha $\geq 80$ for the total score when combining results from previous research utilizing the instrument (Kovacs and Multi-Health Systems 2011).

\section{Physical activity self-efficacy}

Physical activity self-efficacy was measured using the Physical Activity Self-Efficacy Scale (PASES). The PASES is a 17-item self-report questionnaire that assesses supportseeking behaviors, barriers, and positive alternatives in relation to physical activity in children. The responses are assessed using a dichotomous scale allowing the child to select yes or no to each question. One point was awarded for each yes response, and zero points were awarded for a no response. Scores in each category were summed for an overall total score of 17; the highest attainable scores for each section were 7 for support seeking, 4 for barriers, and 6 for positive alternatives (Saunders et al. 1997). There were no specific cutoff scores to indicate low, moderate, or high physical activity self-efficacy. Higher scores are indicative of positive outcomes in all categories. In addition, it is important to note that higher scores for the barriers category are counterintuitive, as they indicate that fewer barriers to physical activity were self-reported (e.g., "I think I can be physically active even if it is hot or cold outside"). For the purpose of this study, scores were reported for each category and the PASES overall total.

To determine the instrument's psychometric properties, researchers (Saunders et al. 1997) administered the scale to 421 predominantly AA fifth graders in rural South Carolina. Participants were randomized into two subgroups. One subgroup consisted of $80 \%$ of the sample's responses, and they were used for psychometric development of the scales. Test-retest data were also collected from the remaining $20 \%$ to establish reliability and validity. Results from the total and retest sample include the following: support seeking $(n=319$, Cronbach's alpha $=0.71 ; n=85$, test-retest reliability $=0.76)$; barriers $(n=323$, Cronbach's alpha $=$ $0.71 ; n=85$ test-retest reliability $=0.82)$; and positive alternatives $(n=321$, Cronbach's alpha $=0.54 ; n=85$, test-retest reliability $=0.61)($ Saunders et al. 1997).

\section{Data Analyses}

Data obtained from BMI measurements and self-reported questionnaires on depressive symptoms and physical activity 
self-efficacy were analyzed utilizing correlational methods. All hypotheses were tested using an estimated correlation coefficient; therefore, calculating an appropriate effect size to determine the magnitude of variable associations, sample size, and level of alpha was especially critical (Cohen 1988). A power analysis was completed using Statistical Analysis System (SAS) version 9.3; $N=62$ was determined to be a suitable sample size, and an estimated correlation coefficient of 0.25 with a $p$ value $\leq 0.05$ for a two-tailed test was found to be sufficient. Cohen's criterion for corresponding estimated correlation coefficients was used to establish a small $(r=$ $0.10)$ and medium $(r=0.30)$ effect size for the study (Cohen 1992). Descriptive statistics were calculated using data from the Demographic Profile Questionnaire, CDI 2, PASES, and child anthropometric assessment. Means, standard deviations, and ranges were calculated for child age, weight, height, BMI $Z$-score, depressive symptoms scores (CDI 2), and physical activity self-efficacy scores (PASES). Frequencies were reported for demographic characteristics (i.e., gender, medical conditions, grade in school), BMI categories, and depressive symptom categories as appropriate. Pearson product-moment correlation coefficient estimates were used to examine the associations between child depressive symptoms, BMI Zscore, and physical activity self-efficacy. Although $p$ values of $\leq 0.05$ were considered statistically significant in the study, $p$ values $\leq 0.10$ for associations were included in order to assist with future modeling.

\section{Results}

Three hypotheses were tested in this study. It was hypothesized that children's depressive symptoms would be positively associated with their BMI Z-score, that their depressive symptoms would be negatively associated with their physical activity self-efficacy, and that their BMI Zscores would be negatively associated with their physical activity self-efficacy. Results from 65 AA children were analyzed for the study. Demographic characteristics such as ethnicity, gender, medical conditions, and grade level are summarized in Table 1. The means, standard deviations, and ranges for anthropometric measurements, CDI 2 scores, and physical activity self-efficacy scores are presented in Table 2.

\section{Depressive Symptoms and BMI Z-scores}

Twenty-two percent of the sample reported clinically significant depressive symptoms for the overall total score. Children reported elevated to very elevated scores for the functional problems scale (18\%) and for the emotional problems scale $(17 \%)$. The percentage of children with elevated to very elevated scores for the subscales ranged
Table 1 Demographic characteristics

\begin{tabular}{lrr}
\hline Characteristics & $n$ & $\%$ \\
\hline Race & 64 & \\
$\quad$ Black & 1 & 98.46 \\
Black/biracial & & 1.54 \\
Gender & 34 & \\
Female & 31 & 52.31 \\
Male & & 47.69 \\
Medical conditions & 46 & \\
No medical condition & 13 & 70.77 \\
Asthma & 3 & 20.00 \\
ADHD & 1 & 4.62 \\
Hypertension & 1 & 1.54 \\
Type II diabetes & 1 & 1.54 \\
Other & & 1.54 \\
Child's grade level & 2 & 3.08 \\
First & 16 & 24.62 \\
Second & 19 & 18.46 \\
Third & 12 & 20.00 \\
Fourth & 13 & 4.62 \\
Fifth & 3 & \\
Sixth & & \\
\hline
\end{tabular}

Table 2 Anthropometric measurements, CDI 2, and physical activity self-efficacy assessments

\begin{tabular}{lrrl}
\hline Variable & Mean & SD & Range \\
\hline Anthropometric measurements & & & \\
$\quad$ Age in years & 8.45 & 1.19 & $7-10$ \\
Weight in pounds & 84.88 & 4.26 & $47.6-211$ \\
Height in inches & 54.00 & 30.94 & $47-63$ \\
Child BMI Z-score & 0.95 & 1.06 & -1.66 to 2.67 \\
CDI 2 T-scores & & & \\
Total & 55.88 & 9.93 & $40-80$ \\
Emotional problems & 54.69 & 9.35 & $42-78$ \\
Negative mood/physical symptoms & 55.55 & 12.07 & $42-90$ \\
Negative self-esteem & 51.71 & 8.51 & $44-90$ \\
Functional problems & 56.09 & 11.68 & $40-90$ \\
Ineffectiveness & 53.71 & 10.95 & $40-90$ \\
Interpersonal problems & 56.28 & 14.33 & $42-90$ \\
PASES scores & & & \\
Total & 11.68 & 2.78 & $4-17$ \\
Support seeking & 5.80 & 1.34 & $2-7$ \\
Barriers & 2.02 & 1.32 & $0-4$ \\
Positive alternatives & 3.85 & 1.43 & $1-6$ \\
\hline
\end{tabular}

CDI 2 Children's Depression Inventory $2^{\mathrm{TM}}, B M I$ body mass index, PASES Physical Activity Self-Efficacy Scale 
Table 3 Summary of estimated correlation coefficients of the CDI 2, BMI Z-score, and PASES

\begin{tabular}{lcrllll}
\hline & \multirow{2}{*}{$\begin{array}{l}\text { BMI Z- } \\
\text { score }\end{array}$} & PASES & & & \\
\cline { 3 - 6 } & & SETS & SS & B & PA \\
\hline CDI 2 & & & & & \\
Total score & 0.187 & -0.078 & -0.115 & 0.177 & -0.163 \\
Emotional problems & 0.123 & 0.014 & -0.026 & $0.226^{\dagger}$ & -0.158 \\
Negative mood/ & 0.119 & 0.003 & 0.021 & 0.108 & -0.144 \\
physical symptoms & & & & & \\
Negative/self-esteem & 0.053 & 0.030 & -0.082 & $0.309^{*}$ & -0.089 \\
Functional problems & 0.187 & -0.140 & -0.171 & 0.088 & -0.126 \\
Ineffectiveness & 0.101 & -0.162 & -0.145 & -0.067 & -0.038 \\
Interpersonal & $0.234^{\dagger}$ & -0.122 & $-0.244^{\dagger}$ & $0.231^{\dagger}$ & $-0.213^{\dagger}$ \\
problems & & & & & \\
BMI Z-score & - & $0.250^{*}$ & $0.231^{\dagger}$ & $0.249^{*}$ & 0.036 \\
\hline Al & & &
\end{tabular}

All associations were estimated with Pearson product-moment correlation coefficients

CDI 2 Child Depression Inventory $2^{\mathrm{TM}}, B M I$ body mass index, PASES Physical Activity Self-Efficacy Scale, SETS self-efficacy total score, $S S$ support seeking, $B$ barriers, $P A$ positive alternatives

$* p \leq 0.05$

${ }^{\dagger} p \leq 0.10$

from $25 \%$ for negative mood/physical symptoms, $25 \%$ for interpersonal problems, $12 \%$ for ineffectiveness, and $1 \%$ for negative self-esteem. Approximately $48 \%$ of the sample was categorized in the overweight-obese BMI range (12\% overweight and $36 \%$ obese). Pearson product-moment correlation coefficients were estimated to quantify associations among depressive symptoms and BMI Z-scores and are summarized in Table 3. A positive correlation existed between interpersonal problems on the CDI 2 and BMI Zscore $(r=0.234, p=0.064)$. This indicates that children with higher BMI Z-scores were more likely to have higher scores on the interpersonal problems subscale.

\section{Depressive Symptoms and Physical Activity Self-Efficacy}

We assessed the children's physical activity self-efficacy in four categories on the PASES self-report questionnaire: total score, support seeking, barriers, and positive alternatives. Overall, the sample reported high levels of physical activity self-efficacy.

We examined associations between child depressive symptoms and physical activity self-efficacy. Children with higher emotional problem scores reported fewer barriers to being physically active $(r=0.226, p=0.070)$. Children with higher negative self-esteem scores also reported fewer barriers to being physically active $(r=0.309, p=0.010)$. When higher interpersonal problem scores were reported, lower scores for support-seeking physical activity behaviors ( $r=-0.244, p=0.050)$ and positive alternatives to being physically active $(r=-0.213, p=0.088)$ were correlated. However, higher interpersonal problem scores were correlated with fewer barriers to being physically active selfreports $(r=0.231, \quad p=0.064)$. Estimated Pearson product-moment correlation coefficients representing the associations between the CDI 2 and PASES are summarized in Table 3.

\section{BMI Z-scores and Physical Activity}

Lastly, relationships between child BMI Z-score and physical activity self-efficacy were examined (Table 3 ). Child BMI Z-score was positively associated with increases in overall physical activity self-efficacy $(r=0.250, p=$ $0.045)$, support-seeking behaviors $(r=0.231, p=0.065)$, and barriers to physical activity $(r=0.249, p=0.045)$.

\section{Discussion}

The current study was conducted to examine associations among depressive symptoms, obesity, and physical activity self-efficacy in AA children. Few investigators have explored the relationships of these variables in a comprehensive fashion. Moreover, previous studies involving obesity and depression in AA populations have focused on adults and adolescents, and there is an evident lack of information in the study's sample population. Although the current study was an exploration of these associations and effect sizes were small to medium, findings can inform future research and assist clinicians in treating obesity and depression in children. More importantly, this study is unique to the exploration of depressive symptoms and physical activity self-efficacy in AA children 7-10 years of age.

The results of this study indicate that $22 \%$ of the sample responded in the range of very elevated total scores for depressive symptoms on the CDI 2 , which was significantly higher than the national average of 3\% for this age group (Anxiety and Depression Association of America 2016). This highlights the issue that depression statistics reported in children may be well below the actual percentage of children living with this disorder. Screening for depression in this age group is not routinely conducted, and there is a paucity of information on the benefits of treatment in children detected through screenings (Siu and US Preventive Services Task Force 2016). In part, many children have barriers to seeking treatment due to negative attitudes, stigmas, and a lack of trust and knowledge of symptoms associated with mental health disorders (Gulliver et al. 2010; Valdez et al. 2019). 
In addition, interpersonal problems had the highest average of all depressive symptoms for the children participants. This is an important finding for parents and researchers because past research has identified that interpersonal problems can be a predictor of depression in early maturing girls and boys (Rudolph et al. 2014).

When examining depressive symptoms and weight relationships among participants, the only statistically significant correlation that we found occurred between interpersonal problems and BMI Z-scores $(p=0.060)$. This finding is congruent with past studies relating obesity in youth to interpersonal problems, such as bullying. In a systematic review of the literature, Midei and Matthews (2011) found positive associations between interpersonal violence in youth, such as bullying and caregiver violence, and the development of obesity. Moreover, researchers have identified that overweight adolescents are more likely to experience interpersonal problems because of exposure to verbal abuse and lack of support by peers (Ames and Leadbeater 2017). Although the literature presents an array of information on the relationship between depression and obesity, there is not a consensus regarding which condition is the causal factor for the other.

Several associations between depressive symptoms and physical activity self-efficacy subcategories were correlated as predicted. Improving self-efficacy through physical activities can assist individuals in achieving better selfperception and alleviating depressive symptoms. It has been well documented that increases in physical activity can improve emotional, physical, and mental health, especially in the reduction of depression in youth and adults (Landry and Driscoll 2012; Parker et al. 2016). Physical activity selfefficacy is also moderately correlated with prosocial behaviors in children, such as cooperating, following directions, and giving verbal praise to members while playing on a sports team (XiaoXia et al. 2016). In the current study, participants with increased interpersonal problems reported a reduction in positive alternatives to being physically active and decreased support-seeking physical activity behaviors. These findings are to be expected because children with interpersonal problems have difficulties connecting with family and friends and usually display feelings of avoidance and isolation (Kovacs and Multi-Health Systems 2011).

However, this study found that children with increased negative mood/self-esteem, emotional problems, and interpersonal problems reported fewer barriers to being physically active. This was inconsistent with the findings of previous studies. The PASES questioned whether each child could still be physically active if there were hot or cold weather conditions, if their day was very busy, if they were tired, or if they had homework to complete. One potential explanation for these findings is that children with emotional or social issues relating to depressive symptoms may also experience social isolation from peers (Matthews et al. 2015); therefore, they are more likely to participate in solitary physical activity and, as a result, the barriers addressed by the survey instrument would not hinder them from being physically active. Moreover, previous research has found increased mental health in adolescents who participate in team sports and group physical activity, in comparison to those who participate in individualized physical activity (Doré et al. 2016).

Similar to the unexpected correlations between depressive symptoms and barriers to physical activity self-efficacy, children with higher BMI Z-scores reported higher physical activity self-efficacy support-seeking behaviors as well as fewer barriers to being physically active. Current research suggests that childhood obesity is associated with decreased physical activity and lower physical activity selfefficacy (Wilkie et al. 2018). Considering that physical activity was not measured in this study, it is possible that children with higher BMI Z-scores did participate in physical activities, but the physical activity was less vigorous in intensity and for shorter periods. Therefore, barriers to being physically active would not present as a problem for them.

In addition, we found no difference between genders in the prevalence of overweight and obese participants and physical activity self-efficacy, although studies have shown that young boys are more physically active than girls and that AA boys have a lower prevalence of obesity than AA girls (18.4 and 20.7\%) (Hinkley et al. 2008; Trust for America's Health \& Robert Wood Johnson Foundation 2018). Overall, high self-efficacy for physical activity was seen in all participants regardless of BMI or gender. While this study did not incorporate objective measurements of physical activity or fitness, the positive relationship between BMI Z-scores and physical activity self-efficacy holds promise for increasing physical activity in children, even among children with higher BMIs.

Multiple limitations for this study were identified. Both the study sample size $(n=65)$ and the magnitude of several correlations were small; thus, recommendations must be made cautiously. $p$ values $\leq 0.10$ for associations were included to assist with future modeling. Multiple correlations were calculated, which could lead to an increased risk of Type I error. Participants were recruited during the spring and summer months and for a 1-week period during the winter. Future studies should recruit for a 12-month period to assure that depressive symptoms are not influenced by seasonal affects. In addition, the CDI 2 is a better fit for use during school months, considering that one question is related to the child's schoolwork and enjoyment of school in the past 2 weeks. The term physical activity was unfamiliar to several children below the 
age of 9 years. The researcher recognized this and had to explain the term before children could answer the physical activity self-efficacy questionnaire. Future studies should include pictures of people performing various physical activities for younger respondents to better comprehend the terminology. However, the pictures would need testing and evaluation to ensure that they correctly depict physical activities, are age appropriate, and are comprehensible to the child. The behavioral factor of being physically active was not directly measured, and future research should employ the use of pedometers in young children to better quantify the level of physical activity for accuracy.

Though depression and obesity are two distinct conditions with separate trajectories for etiology, similarities between their developmental pathways have been investigated. However, further research is needed to confirm these suggestions in pediatric populations. For example, the neurotransmitter serotonin, which can affect mood and appetite, has also been linked with irregularities and decreased levels in individuals with obesity and also those with depression (Buckley et al. 2014; Zhao et al. 2013). Lastly, it is important for researchers to recognize how several childhood depressive symptoms parallel those of obesity. In both conditions, the child can present with sleep disturbances, increases in appetite, and decreases in physical activity (Reeves et al. 2008).

The global prevalence of childhood depression and obesity are steadily increasing despite the abundance of preventative information and interventions available. AA children have disproportionally higher rates of overweight and obese BMIs than White counterparts (Alliance for a Healthier Generation 2016; Centers for Disease Control and Prevention 2015b). Nationally, lower percentages of AAs meet the suggested guidelines for daily physical activity in comparison to other races (U.S. Department of Health and Human Services Office of Minority Health 2017). For these reasons, it is important to create healthy interventions that can be effective for weight-loss and weight-management strategies for AA children. Unlike obesity, the prevalence of depression among young AA children in comparison with other races is underreported and understudied within the literature. It is of equal importance that depression-screening tools appropriately capture depressive symptoms in AA children, thus increasing the chance for a proper diagnosis. Depression preventative measures should be further researched to identify possible strategies to reduce the risk of depression in this population. This study was significant in adding information to the literature on preadolescent AA children with depressive symptoms and the relationships with their BMI and physical activity self-efficacy, sampled from an urban community setting.
Author Contributions All authors contributed to the study conception and design. Material preparation, data collection, and analysis were performed by Y.V.W. The first draft of the paper was written by Y.V. W. All of the authors commented on previous versions of the paper. All authors read and approved the final paper.

\section{Compliance with Ethical Standards}

Conflict of Interest The authors declare that they have no conflict of interest.

Ethical Approval The Institutional Review Board of the University of Tennessee Health Science Center (UTHSC) approved this study, and the study adhered to their ethical standards. Also, the Shelby County School System Office of Planning and Accountability approved this study for schools within their district.

Informed Consent Written informed consent was obtained from the parent of every child participant. Children, 8 years and over, provided written assent before participating in the study.

Publisher's note Springer Nature remains neutral with regard to jurisdictional claims in published maps and institutional affiliations.

\section{References}

Alliance for a Healthier Generation. (2016). About childhood obesity. https://www.healthiergeneration.org/about_childhood_obesity/ get_informed/.

American Heart Association. (2014). Overweight in children. http://www.heart.org/HEARTORG/GettingHealthy/Hea lthierKids/ChildhoodObesity/Overweight-in-Children_UCM_ 304054_Article.jsp.

Ames, M., \& Leadbeater, B. (2017). Overweight and isolated: The interpersonal problems of youth who are overweight from adolescence into young adulthood. International Journal of Behavioral Development, 41(3), 390-404.

Anxiety and Depression Association of America. (2016). Anxiety and depression in children. https://adaa.org/living-with-anxiety/ children/anxiety-and-depression\#.

Assari, S., \& Caldwell, C. H. (2017). Neighborhood safety and major depressive disorder in a national sample of black youth; gender by ethnic differences. Children, 4(2), 14. https://doi.org/10.3390/ children 4020014.

Auerbach, R. (2015). Depression in adolescents: causes, correlates and consequences. Psychological Science Agenda. Retrieved from https://www.apa.org/science/about/psa/2015/11/depression-a dolescents.

Bandura, A. (1989). Human agency in social cognitive theory. American Psychologist, 44(9), 1175-1184.

Barton, A. W., Beach, S. R., Kogan, S. M., Stanley, S. M., Fincham, F. D., Hurt, T. R., \& Brody, G. H. (2015). Prevention effects on trajectories of African American adolescents' exposure to interparental conflict and depressive symptoms. Journal of Family Psychology, 29(2), 171-179. https://doi.org/10.1037/fa m0000073.

Buckley, N. A., Dawson, A. H., \& Isbister, G. K. (2014). Serotonin syndrome. British Medical Journal, 348, 1626. https://doi.org/10. 1136/bmj.g1626.

Centers for Disease Control and Prevention. (2015a). About adult bmi. http://www.cdc.gov/healthyweight/assessing/bmi/adult_bmi/ index.html\#Interpreted. 
Centers for Disease Control and Prevention. (2015b). Prevalence of self-reported obesity among Non-Hispanic Black adults by state and territory, BRFSS, 2012-2014. http://www.cdc.gov/obesity/da ta/table-non-hispanic-black.html.

Centers for Disease Control and Prevention. (2018a). About child \& teen BMI. Retrieved from https://www.cdc.gov/healthyweight/a ssessing/bmi/childrens_bmi/about_childrens_bmi.html.

Centers for Disease Control and Prevention. (2018b). Childhood obesity facts. https://www.cdc.gov/obesity/data/childhood.html.

Cohen, J. (1988). Statistical power analysis for the behavioral sciences. 2nd ed. Hillsdale, NJ: Lawrence Erlbaum Associates.

Cohen, J. (1992). A power primer. Psychological Bulletin, 112(1), 155-159.

Coleman, M. T., \& Newton, K. S. (2005). Supporting selfmanagement in patients with chronic illness. American Family Physician, 72(8), 1503-1510.

Derry, H. M., Padin, A. C., Kuo, J. L., Hughes, S., \& Kiecolt-Glaser, J. K. (2015). Sex differences in depression: does inflammation play a role? Current Psychiatry Reports, 17(10), 78. https://doi.org/10. 1007/s11920-015-0618-5.

Dishman, R. K., Motl, R. W., Sallis, J. F., Dunn, A. L., Birnbaum, A. S., Welk, G. J., \& Jobe, J. B. (2005). Self-management strategies mediate self-efficacy and physical activity. American Journal of Preventive Medicine, 29(1), 10-18. https://doi.org/10.1016/j. amepre.2005.03.012.

Doré, I., O’Loughlin, J. L., Beauchamp, G., Martineau, M., \& Fournier, L. (2016). Volume and social context of physical activity in association with mental health, anxiety and depression among youth. Preventive Medicine, 91, 344-350. https://doi.org/10. 1016/j.ypmed.2016.09.006.

English, D., Lambert, S. F., \& Ialongo, N. S. (2014). Longitudinal associations between experienced racial discrimination and depressive symptoms in African American adolescents. Developmental Psychology, 50(4), 1190-1196. https://doi.org/10. 1037/a0034703.

Flanagan, E. W., \& Perry, A. C. (2018). Perception of physical fitness and exercise self-efficacy and its contribution to the relationship between body dissatisfaction and physical fitness in female minority children. International Journal of Environmental Research and Public Health, 15(6), 1187 https://doi.org/10.3390/ ijerph15061187.

Gu, X., Chen, Y.-L., Jackson, A. W., \& Zhang, T. (2018). Impact of a pedometer-based goal-setting intervention on children's motivation, motor competence, and physical activity in physical education. Physical Education and Sport Pedagogy, 23(1), 54-65. https://doi.org/10.1080/17408989.2017.1341475.

Gulliver, A., Griffiths, K. M., \& Christensen, H. (2010). Perceived barriers and facilitators to mental health help-seeking in young people: a systematic review. BMC Psychiatry, 10(1), 113. https:// doi.org/10.1186/1471-244X-10-113.

Hamilton, K., Warner, L. M., \& Schwarzer, R. (2017). The role of selfefficacy and friend support on adolescent vigorous physical activity. Health Education \& Behavior, 44(1), 175-181. https:// doi.org/10.1177/1090198116648266.

Han, J. C., Lawlor, D. A., \& Kimm, S. Y. (2010). Childhood obesity. The Lancet, 375(9727), 1737-1748. https://doi.org/10.1016/ S0140-6736(10)60171-7.

Hinkley, T., Crawford, D., Salmon, J., Okely, A. D., \& Hesketh, K. (2008). Preschool children and physical activity: a review of correlates. American Journal of Preventive Medicine, 34(5), 435-441. https://doi.org/10.1016/j.amepre.2008.02.001.

Kovacs, M., Multi-Health Systems. (2011). Children's depression inventory. 2nd ed. TO, Canada: MHS

Kumar, S., \& Kelly, A. S. (2017). Review of childhood obesity: from epidemiology, etiology, and comorbidities to clinical assessment and treatment. Mayo Clinic Proceedings, 92(2), 251-265. https:// doi.org/10.1016/j.mayocp.2016.09.017.

Lakshman, R., Elks, C. E., \& Ong, K. K. (2012). Childhood obesity. Circulation, 126(14), 1770-1779. https://doi.org/10.1161/ CIRCULATIONAHA.111.047738.

Landry, B. W., \& Driscoll, S. W. (2012). Physical activity in children and adolescents. $P M \& R, 11(4), 826-832$. https://doi.org/10. 1016/j.pmrj.2012.09.585.

Lorig, K. R., \& Holman, H. R. (2003). Self-management education: history, definition, outcomes, and mechanisms. Annals of Behavioral Medicine, 26(1), 1-7. https://doi.org/10.1207/ S15324796ABM2601_01.

Matthews, T., Danese, A., Wertz, J., Ambler, A., Kelly, M., Diver, A., \& Arseneault, L. (2015). Social isolation and mental health at primary and secondary school entry: a longitudinal cohort study. Journal of the American Academy of Child and Adolescent Psychiatry, 54(3), 225-232. https://doi.org/10.1016/j.jaac.2014. 12.008 .

Mazurka, R., Wynne-Edwards, K. E., \& Harkness, K. L. (2018). Sex differences in the cortisol response to the Trier Social Stress Test in depressed and nondepressed adolescents. Clinical Psychological Science, 6(3), 301-314. https://doi.org/10.1177/ 2167702617739973.

Mental Health America. (2018). Depression in teens. http://www. mentalhealthamerica.net/conditions/depression-teens.

Merikangas, K. R., He, J.-p, Burstein, M., Swanson, S. A., Avenevoli, S., Cui, L., \& Swendsen, J. (2010). Lifetime prevalence of mental disorders in US adolescents: results from the National Comorbidity Survey Replication-Adolescent Supplement (NCS-A). Journal of the American Academy of Child and Adolescent Psychiatry, 49 (10), 980-989. https://doi.org/10.1016/j.jaac.2010.05.017.

Midei, A., \& Matthews, K. A. (2011). Interpersonal violence in childhood as a risk factor for obesity: a systematic review of the literature and proposed pathways. Obesity Reviews, 12(5), e159-e172. https://doi.org/10.1111/j.1467-789X.2010.00823.

National Institute of Mental Health. (2016). Depression basics. https://www.nimh.nih.gov/health/publications/depression/ depressionbasics-508-01112017_150043.pdf.

Office of Disease Prevention and Health Promotion. (2016). Chapter 3: active children and adolescents. http://health.gov/paguidelines/ guidelines/chapter3.aspx.

Ogden, C. L., Carroll, M. D., Lawman, H. G., Fryar, C. D., KruszonMoran, D., Kit, B. K., \& Flegal, K. M. (2016). Trends in obesity prevalence among children and adolescents in the United States, 1988-1994 through 2013-2014. JAMA, 315(21), 2292-2299. https://doi.org/10.1001/jama.2016.6361.

Parker, A. G., Hetrick, S. E., Jorm, A. F., Mackinnon, A. J., McGorry, P. D., Yung, A. R., \& Purcell, R. (2016). The effectiveness of simple psychological and physical activity interventions for high prevalence mental health problems in young people: a factorial randomised controlled trial. Journal of Affective Disorders, 196, 200-209. https://doi.org/10.1016/j.jad.2016.02.043.

Reeves, G. M., Postolache, T. T., \& Snitker, S. (2008). Childhood obesity and depression: connection between these growing problems in growing children. International Journal of Child Health and Human Development, 1(2), 103. https://doi.org/10.1016/j.jad. 2016.02 .043$.

Rudolph, K. D., Troop-Gordon, W., Lambert, S. F., \& Natsuaki, M. N. (2014). Long-term consequences of pubertal timing for youth depression: identifying personal and contextual pathways of risk. Development and Psychopathology, 26(4pt2), 1423-1444. https://doi.org/10.1017/S0954579414001126.

Saunders, R. P., Pate, R. R., Felton, G., Dowda, M., Weinrich, M. C., Ward, D. S., \& Baranowski, T. (1997). Development of questionnaires to measure psychosocial influences on children's 
physical activity. Preventive Medicine, 26(2), 241-247. https:// doi.org/10.1006/pmed.1996.0134.

Siu, A. L., US Preventive Services Task Force. (2016). Screening for depression in children and adolescents: US Preventive Services Task Force Recommendation Statement. Pediatrics, 137(3), 1-8. https://doi.org/10.1542/peds.2015-4467.

Sommer, A., \& Twig, G. (2018). The impact of childhood and adolescent obesity on cardiovascular risk in adulthood: a systematic review. Current Diabetes Reports, 18(10), 91. https://doi.org/10. 1007/s11892-018-1062-9.

The Children's Hospital of Philadelphia. (2016). Pediatric Z-score Calculator. http://stokes.chop.edu/web/zscore/.

Trust for America's Health \& Robert Wood Johnson Foundation. (2018). Obesity rates \& trends overwiew. https://stateofobesity. org/obesity-rates-trends-overview/.

U.S. Department of Health and Human Services \& National Institute of Mental Health. (2015). Depression. http://www.nimh.nih.gov/ health/publications/depression-what-you-need-to-know-12-2015/ depression-what-you-need-to-know-pdf_151827.pdf.

U.S. Department of Health and Human Services Office of Minority Health. (2017). Obesity and African Americans. https:// minorityhealth.hhs.gov/omh/browse. aspx ?lvl=4\&lvlid $=25$.

U.S. Department of Health and Human Services President's Council on Fitness Sports \& Nutrition. (2015). Facts \& statistics. http://www.fitness.gov/resource-center/facts-and-statistics/.

Valdez, C. R., Rodgers, C. R., Gudiño, O. G., Isaac, P., Cort, N. A., Casas, M., \& Butler, A. M. (2019). Translating research to sup- port practitioners in addressing disparities in child and adolescent mental health and services in the United States. Cultural Diversity and Ethnic Minority Psychology, 25(1), 126-135. https://doi.org/ 10.1037/cdp0000257.

Washington, T., Rose, T., Coard, S. I., Patton, D. U., Young, S., Giles, S., \& Nolen, M. (2017). Family-level factors, depression, and anxiety among African American children: a systematic review. Child \& Youth Care Forum, 46(1), 137-156.

Wilkie, H. J., Standage, M., Gillison, F. B., Cumming, S. P., \& Katzmarzyk, P. T. (2018). Correlates of intensity-specific physical activity in children aged 9-11 years: a multilevel analysis of UK data from the International Study of Childhood Obesity, Lifestyle and the Environment. British Medical Journal Open, 8 (2), e018373. https://doi.org/10.1136/bmjopen-2017-01837.

Williams, H. G., Pfeiffer, K. A., O’Neill, J. R., Dowda, M., McIver, K. L., Brown, W. H., \& Pate, R. R. (2008). Motor skill performance and physical activity in preschool children. Obesity, 16(6), 1421-1426. https://doi.org/10.1038/oby.2008.214.

XiaoXia, S., Ping, X., McBride, R. E., JiLing, L., \& Thornton, M. A. (2016). At-risk boys' social self-efficacy and physical activity self-efficacy in a summer sports camp. Journal of Teaching in Physical Education, 35(2), 159-168. https://doi.org/10.1123/jtpe. 2014-0176.

Zhao, J., Goldberg, J., \& Vaccarino, V. (2013). Promoter methylation of serotonin transporter gene is associated with obesity measures: a monozygotic twin study. International Journal of Obesity, 37 (1), 140-145. https://doi.org/10.1038/ijo.2012.8. 